\title{
Research on the Innovation of Military Professional Education Mode in the Internet Era
}

\author{
Yan-mei $\mathrm{WU}^{1}$ and Kai GUO${ }^{2}$ \\ ${ }^{1}$ Joint Service College, Beijing, China \\ ${ }^{2}$ Beijing Institute Tracking and Telecommunications Technology, Beijing, China
}

Keywords: Internet, Military Professional Education, Mode innovation.

\begin{abstract}
Military professional education in the Internet age needs new methods to meet the requirements of the trainees' individualized learning. MOOC, Inverted Classroom and Micro Lecture provide useful means for the innovative development of the military professional education. With the help of these new methods, the military professional education will further improve military personnel's knowledge structure, enhance their working abilities and promote their career development.

The rapid development of network technology has greatly changed all aspects of human society, such as the emergence of the "Internet + education" model, which reformed the education technology, altered the education system, changed the education concept, and innovated the teaching methods. Among them, as a form of education for cultivating high-quality talents, military professional education should make full use of the internet technology to enhance the quality and effectiveness of professional education.
\end{abstract}

\section{The Basic Connotation of Vocational Education}

Professional education is a planned and continuous educational practice activity for all military personnel in accordance with the requirements of military professional talents for armed forces and war's development. Its goals are to expand military professional traits, make innovations for its professional quality [1]. In the new talent cultivation system, military professional education has the distinct characteristics, such as the clear objectives, full participation, diverse contents, flexible teaching form as well as the persistence of educational process[2,3].

The first is targeted education. Military professional education should have the basic goal of improving the working abilities and career development potentials by focusing on the enhancing the capabilities of preparing for war, and aiming at improving the core competencies and professionalism.

The second is the full range of educational objects. The objects of military professional education are all military personnel including civilian staff. Everyone has the obligation and responsibility to participate in military professional education.

The third is the diversity of educational contents. The contents of military professional education center on the needs of armed forces and the requirements of individual talents, which focuses on learning new theories, equipments, technologies, and builds a content system that is generally applicable to the optimization of knowledge structure and the improvement of professional quality.

The fourth is the flexibility of education forms. Military professional education emphasizes autonomic learning, distance learning, and individual studying by using the network.

The fifth is the continuity of the education process. Military staffs receive re-education and re-training at their posts so as to improve themselves constantly.

\section{The Change of Military Professional Education in the Internet Era}

In the Internet era, networks, Ipad, and Wifi have become a part of people's lives, which has not only changed the mode of ordinary professional education, but also prompted the transformation in military professional education. 


\section{The Teaching Goals Change from Knowledge Transfer to Ability Generation}

Knowledge transfer has always been the most basic logic for the cultivation of talents in institutions of higher education. In the traditional teaching model, the teachers mainly give lectures by emphasizing on the "one-way indoctrination" of the knowledge. Most of them focus on learning knowledge, but neglecting the training of students' abilities. In the Internet Era, the military professional education is very different from the traditional teaching model in that it trains students' post-servicing skills and the abilities of solving practical problems. In the teaching process, the teachers always guide students to analyze problems and solve questions. The teaching model oriented to vocational education regards knowledge as the basis of ability generation, and the ability generation in the process of knowledge learning as the basic goal of teaching.

\section{The Teaching Forms are the Coexistence of Individual Learning and Collaborative Cooperation}

In the Internet Era, network learning platform is an important support for the military professional education. It can provide each student with a learning plan, learning resources and learning opportunities that are tailored to each student's needs. At the same time, students and trainees can interact with each other through on-line learning. They can discuss different issues and make learning more openly and cooperatively.

\section{The Teaching Contents are Based on Job Requirement and Problem Traction}

In the Internet Era, the teacher's important task is to implement the structural reorganization of the curriculum contents according to the characteristics of the learning objects, creatively set the systematic knowledge, and present the contents of the teaching based on job requirement and problem traction. By stimulating students' enthusiasm and motivation for active learning, it will have a positive effect on the transfer of knowledge to competence training and quality transformation.

\section{The Teaching Space and Time are Expressed as the Interconnecting between the Inside and the} Outside of the Class

In the past, students were taught in a physical environment such as a classroom or a library. Learning was always restricted by time and place. In the Internet Era, the teaching model could get rid of the constraints of the space and time and achieve a close integration between offline entities and online virtual ones. The first is open content. The network makes high-quality teaching resources form a super information resource library, and realizes the real-time sharing of local resources and remote resources through hyperlinks. The second is structural openness. The use of componentization technology allows the configuration of teaching content to be updated at any time. The third is the open function. The network can provide comprehensive teaching services, support on-demand learning, timely learning and flexible learning.

\section{Innovation of Teaching Mode of Military Professional Education in Internet Era}

The rapid development of the Internet and its wide application in the field of education will have a great impact on military professional education and promote the innovation of its teaching mode. In the emerging new teaching modes, the most representative ones are "MOOC", " Inverted Classroom" and "Micro Lecture".

\section{MOOC}

MOOC (Massive Open Online Course) is a large-scale open online course. It is an online education mode that integrates high-quality curriculum resources and a complete learning experience. [4]. MOOC is based on a platform and has a rigorous teaching mechanism. It adopts the connections between teachers, learners, and platforms as meridians, and uses curriculum learning resources and the massive amounts of data generated from interactions as bone and flesh, so as to form a complete educational ecosystem. It is a combination of curriculum, platform, teaching process and teaching 
philosophy. The MOOC teaching process can be roughly divided into the following four steps. Figure 1 shows the MOOC teaching process.

Course Release. Before the class starts, the teacher will use the course as the basic unit to publish the course information on the platform, including the introduction of the course, the syllabus, the introduction of teachers, the start and end time of the course, as well as the plan of teaching activities.

Course Teaching. After the beginning of the course, the teachers will release course materials regularly, including teaching videos, test questions, courseware, homework and so on. On the basis of guaranteeing the integrity of the curriculum, the teaching content and activities are fragmented, and the instant test questions are arranged after each video unit to achieve the purpose of supervising, testing and consolidating the learning.

The learners can participate in teaching activities such as learning course video, participating test, discussing problem and doing homework. In terms of problem discussion, learners can conduct online learning exchanges, and teachers are responsible for answering questions online. The teachers can also organize offline meetings regularly to meet learner's needs of face-to-face communication.

Course Examination. When the course is over, according to the analysis of learning behavior records, the learners who meet certain conditions can apply for the exam within the prescribed time. At present, some platforms complete course exams through remote terminals, and use online proctoring techniques as well as the integrity requirements of learners to provide limited assurance of the authenticity of academic performance. Others provide exam-based course completion tests by setting up test centers.

Curriculum certification. After completing the course and passing the examination, the learners can get the course certificate. At present, the non-profit MOOC platform is generally free to take part in the course graduation examination, such as Edx, school online, dream lesson learning platform, etc. While the profitable MOOC platform will charge a certain fee to take part in the course test, such as Coursera, Udacity and so on. In addition, the credit evaluation and recognition of MOOC certificate need further research and exploration. The use of credit system and the traditional education mechanism will improve the social recognition of MOOC and stimulate the value of MOOC education.

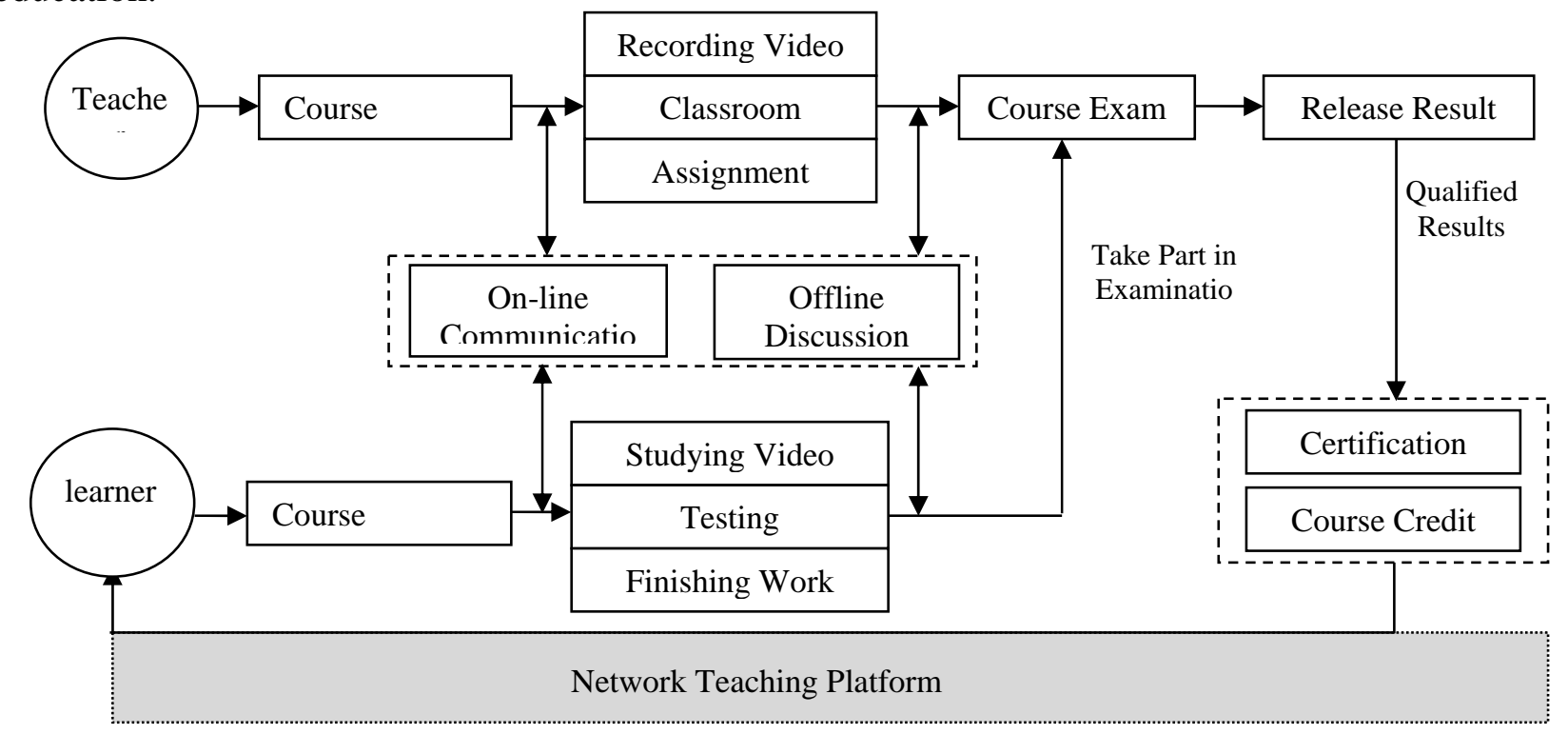

Figure 1. The MOOC teaching process

\section{Inverted Classroom}

Inverted Classroom refers to a new teaching mode by readjusting the time inside and outside of classroom and transferring the decision of learning from teacher to trainee. In this mode, the teaching time in the classroom is mainly used to jointly study and solve the problems so as to gain a deeper understanding. Teachers do not take up class time to teach basic knowledge. These basic knowledge require students to study before class by watching video lectures, listening to podcasts, reading 
e-books, talking to other students on the website, and looking up the materials they need at any time. In the inverted classroom, the class time will be focused on the discussion about the problems so as to realize the transformation of "knowledge transfer" to "absorption internalization"[5]. The teaching process of inverted classroom can be roughly divided into the following four steps. Figure 2 is a schematic diagram of the inverted classroom.

Course Resources Release. Before the class, the teachers publish the theoretical knowledge resources that students should study and master before class, including documents, videos, PPT, micro Lectures, etc., and clarify the list of pre-school learning tasks and guide students to learn independently.

Self-study before Class. Students learn relevant theoretical knowledge through reading curriculum resources such as reading documents, watching videos, courseware, and micro lectures, and prepare questions discussed in class.

Classroom Interactive Learning. Guided by the problem traction, the students will be guided to carry out inquiry-based, seminar-based teaching activities and report the results to achieve so as to realize the internalization of knowledge and the expansion of capabilities.

After Class Test Evaluation. After class, the teaching content test will be carried out, and the teaching effect be evaluated. The teachers will give the directed guidance according to the feedback situation. At the same time, the teaching plan and the curriculum resources will be further optimized.

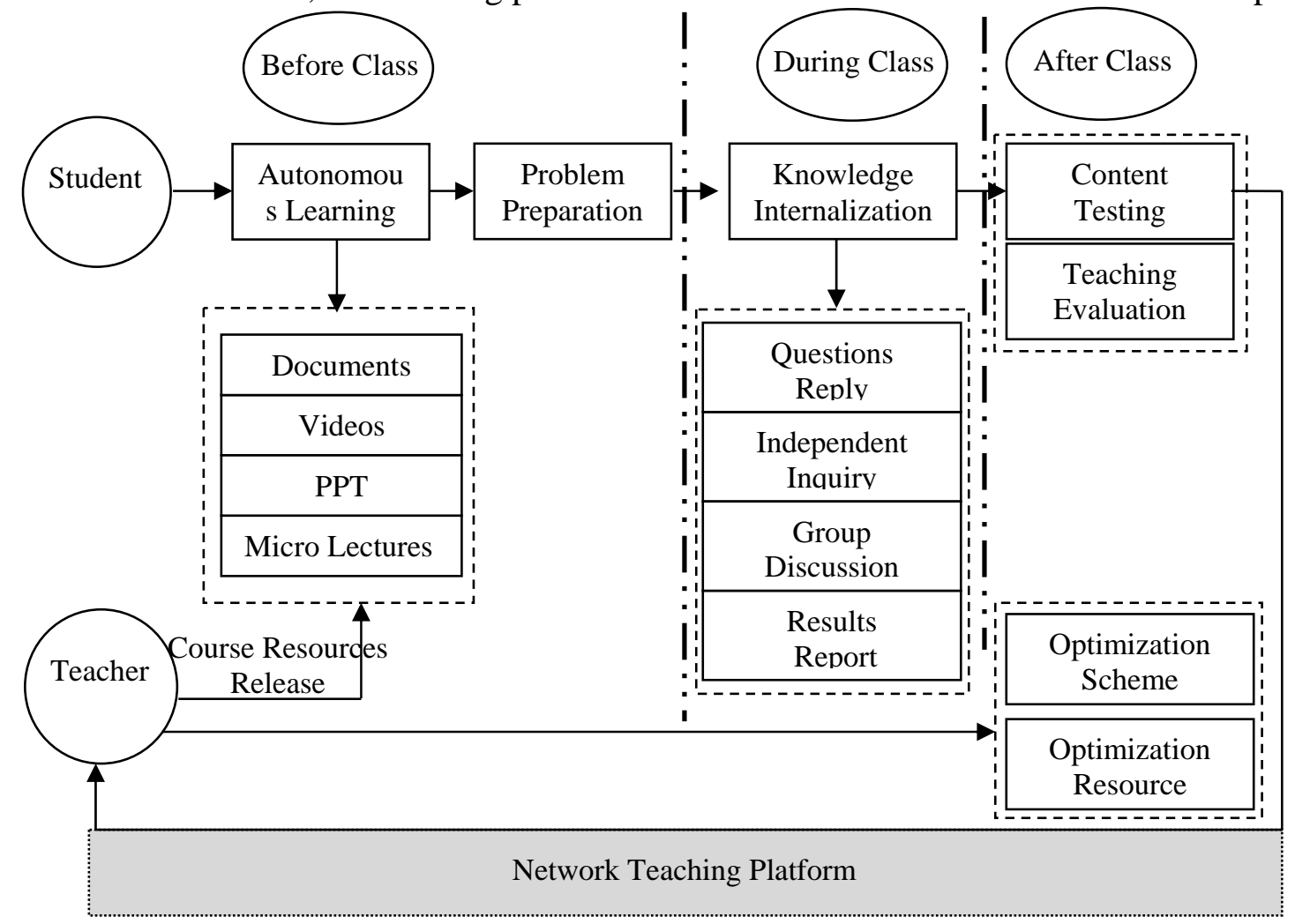

Figure 2. The schematic diagram of the inverted classroom

\section{Micro Lecture}

Micro Lecture is defined as the digital resources by using information technology to show fragmentation of learning contents, process and the structure, in accordance with the law of understanding. The teaching of Micro Lecture is the process of teaching and learning by recording a teacher's knowledge around a certain knowledge point with micro video as the main carrier. The core is the classroom teaching video, in addition to the related teaching design, material courseware, teaching reflection, practice testing and teacher-student interaction and other auxiliary teaching resources. The structured and thematic "small environment" are constructed with a certain organizational relationship and presentation, and as a new type of teaching form in the Internet Era [6]. It has the characteristics of short teaching time, fine teaching content, prominent teaching theme, 
and small capacity of teaching resources. As a new teaching means, Micro Lecture can be used as a pre class study, new lesson introduction, knowledge understanding, and practice consolidation. It can meet the requirements of fragmentation and individualized learning. Figure 3 is a sketch map of the Micro Lecture resources.

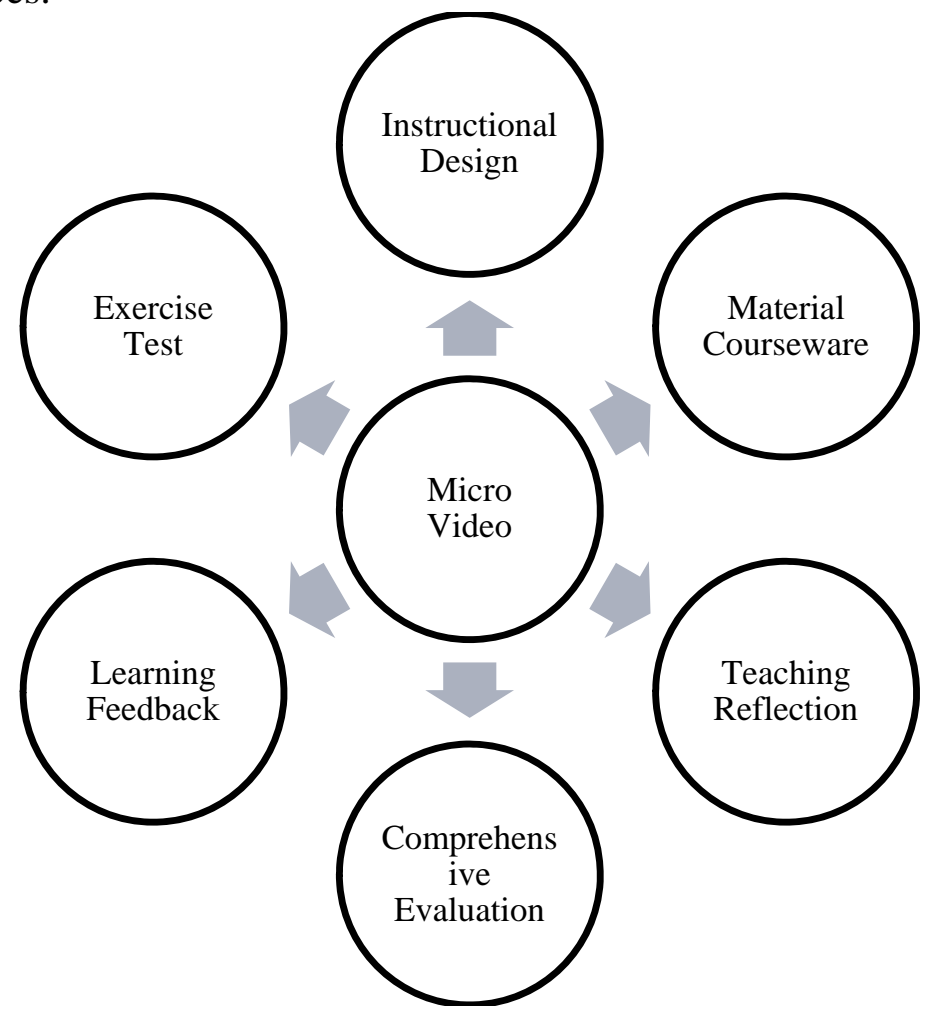

Figure 3. The sketch map of the Micro Lecture resources

\section{Summary}

In the Internet Era, military professional education should keep up with the development trend of the times and achieve cross-developing. It is necessary to carry out profound reforms based on Internet thinking and Internet technologies, broaden military professional education service channels, provide new models of military professional education, and accelerate the in-depth development of military professional.

\section{References}

[1] JIANG Qingjiang, YANG Yi, XIA Hongbo. Military Professional Education in the Perspective of "Trinity". Party history, 2015(8)76-77

[2] JI Weibin. Analysis on Deepening Development of Military Professional Education. Continuing Education, 2016(2)67-69

[3] Interpretation of Military Professional Education Reform by the Central Military Commission: Education Coverage. PengPai News, 2017.12.23

[4] XIONG Longfei, XU Lin. Exploration and Thinking of Military Professional Education Based on MOOC Mode. 21 century Continuing Education Forum, 2014(11)40-41

[5] JU Jingping. Inverted Classroom is the innovation of teaching mode. http://blog.sina.com

[6] Micro Lecture. http://baike.so.com 